\title{
Satellite Thermal Infrared and Inverted Echo Sounder Determinations of the Gulf Stream Northern Edge
}

\author{
PETER CORNILlON AND D. RANDOLPH WATTS \\ Graduate School of Oceanography. University of Rhode Island, Narragansett, RI 02882
}

(Manuscript received 2 November 1986, in final form 3 June 1987)

\begin{abstract}
The northern edge of the Gulf Stream off Cape Hatteras, North Carolina was located in 155 AVHRR-derived maps of sea surface temperature (SST) using five different methods. One method was subjective location of the northern edge by an analyst; the other four involved objective location of the edge by computer using various statistics of the SST field. Specifically, the quantities considered were: maximum SST gradient (calculated over a $3 \times 3$ pixel box), maximum SST (on a pixel-by-pixel basis), maximum variance (calculated over a $7 \times 7$ pixel box), and change in the skewness of the SST distribution (calculated over a $5 \times 5$ pixel box). The resulting locations were compared with the location of the $15^{\circ} \mathrm{C}$ isotherm at $200 \mathrm{~m}\left(T_{15}\right)$ determined from inverted echo sounders (IESs) moored on the sea floor. The best method, which yielded the smallest rms difference from the IES-derived $T_{15}$, was the subjective one; the surface front was located $9.0 \mathrm{~km}$ shoreward of $T_{15}$ with a $\mathrm{ms}$ difference of $14.3 \mathrm{~km}$. The best objective technique used the skew of the SST distribution: Each pixel in the image was replaced by the skew of the distribution of the twenty-five SST values obtained from a $5 \times 5$ pixel square centered on that pixel. The skew changes sign when a step in the SST data, such as the Gulf Stream northern edge, is crossed. The Gulf Stream northern edge located in the skew images was found to be $14.0 \mathrm{~km}$ shoreward of $T_{15}$ in the mean with a rms difference of $18.2 \mathrm{~km}$. In general, the more spatial information used, the better the estimate.
\end{abstract}

\section{Introduction}

Interest in locating the path of the Gulf Stream with radiometers dates back to the early 1950 s. Stommel et al. (1953) assumed that the maximum sea surface temperature (SST) gradient, observed by ship to be near the "inner edge" (northern edge) of the stream, was also observable by airborne radiometer and might be used to locate the Gulf Stream. In three surveys they were able to show that the edge determined by radiometer correlated well with that observed in wide-angle, time-lapse motion pictures taken from the same aircraft. [The relationship between such visual observations and the "inner edge" had been established in Operation Cabot (Fuglister and Worthington, 1951).]

During the same period, Strack (1953) qualitatively examined the relationship between the SST gradient and subsurface measures of the position of the stream. Later, Hansen and Maul (1970) provided a careful quantitative analysis of approximately 100 ship-derived expendable bathythermograph (XBT) sections of the Gulf Stream between Cape Hatteras and $58^{\circ} \mathrm{W}$. In contrast to the work of Strack (1953), Hansen and Maul's (1970) XBT data extended to depths in excess of $200 \mathrm{~m}$ in all cases, the distance between their XBT samples was substantially smaller $(8.7 \mathrm{~km})$, and there were sufficient data to determine the angle at which the ship crossed the stream. (These improvements were all necessary to quantify the results.) Focussing on an analysis of the horizontal distance between the maximum SST gradient and the surface projection of $T_{15}$ (the $15^{\circ} \mathrm{C}$ isotherm at $200 \mathrm{~m}$, the generally accepted definition of the northern edge of the Gulf Stream), Hansen and Maul found a mean shoreward surface offset of $14.5 \mathrm{~km}$, a rms difference of $11.8 \mathrm{~km}$, and a larger offset $(16.2 \mathrm{~km})$ in anticyclonic meanders than in cyclonic meanders $(11.3 \mathrm{~km})$.

More recently, Khedouri (1972), also analyzing approximately 100 XBT transects between New York and Bermuda, concluded that the maximum SST correlates better with $T_{15}$ than does the maximum SST gradient. The transects that he used crossed the mean path of the stream at approximately $90^{\circ}$, but crossed most individual paths at oblique angles; hence, he was unable to provide a quantitative analysis of the data. He noted, however, that the result showing the maximum SST as a better indicator of $T_{15}$ than the maximum SST gradient is not affected by the crossing angle because separation of both surface measures relative to $T_{15}$ have the same dependence on the cosine of the crossing angle. Briefly his results are the following: If $L_{\nabla}$ defines the horizontal distance from the maximum SST gradient to the surface projection of $T_{15}$ (positive for $T_{15}$ seaward) and $L_{\mathrm{MAX}}$ is the distance from the maximum SST to the surface projection of $T_{15}$, he found $L_{\nabla}=59.3 \mathrm{~km}, \sigma_{L_{0}}=112.3 \mathrm{~km}$ and $L_{\mathrm{MAX}}$ 
$=20.6 \mathrm{~km}, \sigma_{L_{\mathrm{MAX}}}=24.0 \mathrm{~km}$. These results are startling when compared to those of Strack (1953) or Hansen and Maul (1970), even taking into account the possibility of oblique crossings of the Gulf Stream. They do, however, raise the intriguing question of a possibly better correlation between $T_{15}$ and the maximum SST. As will be discussed later, the very large mean offsets and standard deviations of $L_{\nabla}$ are probably due to the use of an inappropriate surface front.

Robinson et al. (1974) provided a qualitative comparison of in situ determinations of $T_{15}$ and airborne determinations of the maximum SST gradient but because the ship took several days to define the edge of the stream whereas the aircraft took only several hours, the data were not synoptic and a quantitative comparison was not possible.

A quantitative comparison of the radiometer-derived edge with the edge located in subsurface data is important because airborne and satellite-borne radiometers measure the temperature of only the upper few micrometers of the ocean. Thus, even though the in situ XBT studies quoted above show moderately good agreement between SST characteristics of the Gulf Stream and $T_{15}$, there is no guarantee that radiometrically obtained measures of the edge will agree well with $T_{15}$.

Horton (1984) derived results on this question from an experiment in which the Gulf Stream was surveyed by aircraft eight times in a 15-day period. Airborne XBTs (AXBTs) were used to locate $T_{15}$ while a precision radiation thermometer (PRT) was used to locate the surface track. The objective of the experiment was to examine the effects of a hurricane on the horizontal separation between $T_{15}$ and the maximum SST gradient, hence the limited duration of the study. Prior to the hurricane Horton (1984) found a mean separation of $1 \pm 4 \mathrm{~km}$, while after the hurricane the separation had increased to $19 \pm 4 \mathrm{~km}$.

Horton (1984) makes three points with regard to the SST data which are of significance to the work presented in this paper. First, there are often several fronts in the SST field near $T_{15}$, not just one strong front. Other investigators have also noted that several surface fronts are associated with the Gulf Stream northern edge (Fuglister and Worthington, 1951; Hansen and Maul, 1970; Robinson et al., 1974). Second, these fronts are not continuous along the entire length of the stream. Third, he used the warmest front.

The main problem faced in comparisons between airborne or satellite-borne radiometric determinations of the northern edge of the Gulf Stream and $T_{15}$ is the lack of simultaneity between the two sets of observations. In our study, instead of using XBT data as the in situ measure of $T_{15}$, the satellite-derived front is compared with the position determined from a number of inverted echo sounders (IESs) moored on the sea floor downstream of Cape Hatteras.

\section{Data}

\section{a. Inverted echo sounder data}

The IES, described in detail in Chaplin and Watts (1984), measures the round-trip travel time of a 10$\mathrm{kHz}$ acoustic pulse from the sea floor to the sea surface. Because the sound speed depends on temperature, and the round-trip travel time is the integral of the sound speed over depth, the round-trip travel time is also an approximate measure of the integral of temperature over depth. Assuming a two-layer ocean, the roundtrip travel time can be used to estimate the depth of the main thermocline, which is approximately the $15^{\circ} \mathrm{C}$ isotherm in the region of interest. Given this depth and the shape of the $15^{\circ} \mathrm{C}$ isotherm normal to the northern edge of the stream, the horizontal distance from the IES to $T_{15}$ is readily obtained; this calculation of $T_{15}$ is discussed in detail in Watts and Johns (1982). The rms difference between these IES determinations of $T_{15}$ and those from 15 XBT sections across the Gulf Stream within $2 \mathrm{~km}$ of an IES section was found to be $8 \mathrm{~km}$ (Watts and Johns, 1982), but they estimate that the actual (dynamically important) noise level in the path determinations is approximately $5 \mathrm{~km}$ because of the high coherences between IES-determined stream position at successive downstream sites.

Each IES estimate of $T_{15}$ used in this project was obtained along one of the IES lines shown in Fig. 1, using between 1 and 3 instruments along the line. These IES estimates of $T_{15}$ are a time series of the location of $T_{15}$ along each IES line. Each time series was detided, low-pass filtered (1/24-h corner frequency), and resampled every 12 hours. In order to study the downstream growth rate of meanders, the IESs in the array were moved progressively downstream during the experiment. Table 1 lists the location of each IES for which good data were recovered and its period of de-

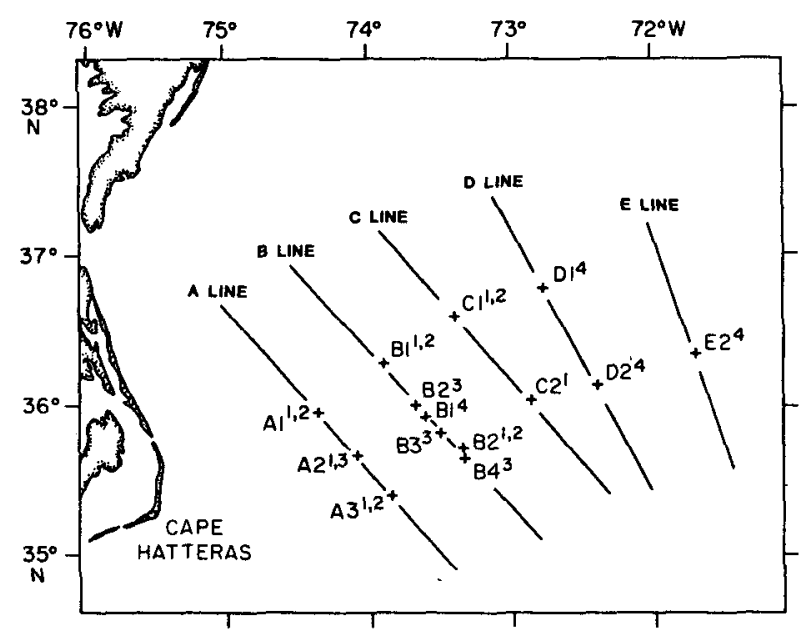

FIG. 1. Map of IES sites and lines. 
TABLE 1. IES deployment summary.

\begin{tabular}{|c|c|c|c|c|}
\hline \multirow[b]{2}{*}{ IES $^{*}$} & \multirow{2}{*}{$\begin{array}{l}\text { Latitude } \\
\left({ }^{\circ} \mathrm{N}\right)\end{array}$} & \multirow{2}{*}{$\begin{array}{c}\text { Longitude } \\
\left({ }^{\circ} \mathrm{W}\right)\end{array}$} & \multicolumn{2}{|c|}{$\begin{array}{l}\text { Deployment period } \\
\text { (day/mo/yr) }\end{array}$} \\
\hline & & & from & to \\
\hline $\mathrm{Al}^{1}$ & $35^{\circ} 57.94$ & $74^{\circ} 21.19$ & $7 / 5 / 79$ & $15 / 8 / 79$ \\
\hline $\mathrm{A} 2^{1}$ & $35^{\circ} 41.08$ & $74^{\circ} 04.91$ & $31 / 5 / 79$ & $15 / 8 / 79$ \\
\hline $\mathrm{A}^{1}{ }^{1}$ & $35^{\circ} 24.95$ & $73^{\circ} 49.98$ & $7 / 5 / 79$ & $15 / 8 / 79$ \\
\hline B $1^{1}$ & $36^{\circ} 17.48$ & $73^{\circ} 53.07$ & $7 / 5 / 79$ & $15 / 8 / 79$ \\
\hline B21 & $35^{\circ} 44.05$ & $73^{\circ} 19.85$ & $7 / 5 / 79$ & $15 / 8 / 79$ \\
\hline $\mathrm{C}_{1}^{1}$ & $36^{\circ} 36.64$ & $73^{\circ} 22.66$ & $7 / 5 / 79$ & $15 / 8 / 79$ \\
\hline $\mathrm{C}_{2}{ }^{\prime}$ & $36^{\circ} 02.97$ & $72^{\circ} 51.13$ & $7 / 5 / 79$ & $15 / 8 / 79$ \\
\hline $\mathrm{Al}^{2}$ & $35^{\circ} 57.96$ & $74^{\circ} 21.19$ & $9 / 11 / 79$ & $14 / 7 / 80$ \\
\hline $\mathrm{A}^{2}$ & $35^{\circ} 24.98$ & $73^{\circ} 49.98$ & $9 / 11 / 79$ & $14 / 7 / 80$ \\
\hline $\mathrm{B} 1^{2}$ & $36^{\circ} 17.56$ & $73^{\circ} 53.05$ & $9 / 11 / 79$ & $14 / 7 / 80$ \\
\hline $\mathrm{B} 2^{2}$ & $35^{\circ} 44.05$ & $73^{\circ} 19.85$ & $9 / 11 / 79$ & $14 / 7 / 80$ \\
\hline $\mathrm{Cl}^{2}$ & $36^{\circ} 36.64$ & $73^{\circ} 22.61$ & $9 / 11 / 79$ & $14 / 7 / 80$ \\
\hline $\mathrm{A} 2^{3}$ & $35^{\circ} 41.16$ & $74^{\circ} 04.29$ & $11 / 11 / 80$ & $6 / 7 / 81$ \\
\hline $\mathrm{B} 2^{3}$ & $36^{\circ} 01.13$ & $73^{\circ} 39.93$ & $11 / 11 / 80$ & $6 / 7 / 81$ \\
\hline $\mathrm{B}^{3}{ }^{3}$ & $35^{\circ} 49.98$ & $73^{\circ} 29.35$ & $11 / 11 / 80$ & $6 / 7 / 81$ \\
\hline $\mathrm{B} 4^{3}$ & $35^{\circ} 39.97$ & $73^{\circ} 19.02$ & $11 / 11 / 80$ & $6 / 7 / 81$ \\
\hline $\mathrm{B} 1^{4}$ & $35^{\circ} 56.80$ & $73^{\circ} 36.00$ & $10 / 7 / 81$ & $6 / 7 / 82$ \\
\hline $\mathrm{D} 1^{4}$ & $36^{\circ} 48.02$ & $72^{\circ} 46.05$ & $11 / 7 / 81$ & $3 / 7 / 82$ \\
\hline $\mathrm{D} 2^{4}$ & $36^{\circ} 09.12$ & $72^{\circ} 22.61$ & $11 / 7 / 81$ & $3 / 7 / 82$ \\
\hline $\mathrm{E} 2^{4}$ & $36^{\circ} 21.96$ & $71^{\circ} 41.86$ & $20 / 11 / 81$ & $5 / 7 / 82$ \\
\hline
\end{tabular}

* The letter prefix designates the IES line on which the instrument was deployed. The superscripts specify the deployment period shown in the two right-hand columns.

ployment. The data, processed as in Watts and Johns (1982) and Tracey and Watts (1986), are used here with the only modification being a linear interpolation in time between consecutive IES observations to obtain $T_{15}$ corresponding to the satellite pass.

\section{b. Satellite data}

The satellite data used were obtained from the Advanced Very High Resolution Radiometer (AVHRR) of the TIROS-N series satellites (Schwalb, 1978). Each pass, which has a 1.1-km resolution at nadir, was earth located (navigated). Following navigation, the data were remapped (rectified) to a common projection to allow for rapid and convenient manipulation. Two of the images used are shown in Fig. 2. Each $X$ in these figures is an IES-derived $T_{15}$. The plus signs mark the locations of the IES instruments. An analysis of approximately 70 passes after navigation and rectification showed a rms error of less than $1 \mathrm{~km}$ in the location of a pixel in the Cape May, New Jersey area. Where both channels 4 and 5 (10.5 to $11.3 \mu \mathrm{m} ; 11.5$ to 12.5 $\mu \mathrm{m})$ were available, the SST field was calculated using the two-channel algorithm of McClain et al. (1983). This was possible only for the NOAA-7 data. For TIROS-N and NOAA-6, the raw radiometer data from channel 4 were used.

Of the numerous passes available, only the 155 that passed a preliminary screening for clouds were used. The screening was generous in that any image which offered a chance of providing an estimate of the northern edge of any of the lines was included. In the actual analysis several of the images selected provided no useful data on any of the IES lines for any of the methods applied. Furthermore, the number of images providing useful data varied with the method.

As indicated earlier, there are often several fronts, or sharp gradients, in the SST field along the northern edge of the Gulf Stream. Furthermore, in at least one study (Khedouri, 1972), the maximum SST was shown to correlate better with $T_{15}$ than the maximum SST gradient did. In light of these observations and others (Gerson and Gaborski, 1977; Gerson et al., 1979), five different criteria for locating the northern edge of the Gulf Stream were defined. One of the objectives of this research was to determine which of the criteria provides the best estimate of $T_{15}$, with the ultimate aim of developing an objective criterion. Each of the methods used is discussed in detail below, followed by an evaluation of the comparisons between the IES and satellite data.

\section{1) MAXIMUM SST GRADIENT (GRAD)}

The use of the sharp SST gradient as a measure of the location of $T_{15}$ by a number of previous investigators has been documented above. In the present work a 3 pixel by 3 pixel $(3 \times 3)$ median operator was passed over each image used. The median operator replaces the center pixel by the median of the nine pixel values and is attractive in that it preserves edges but eliminates 

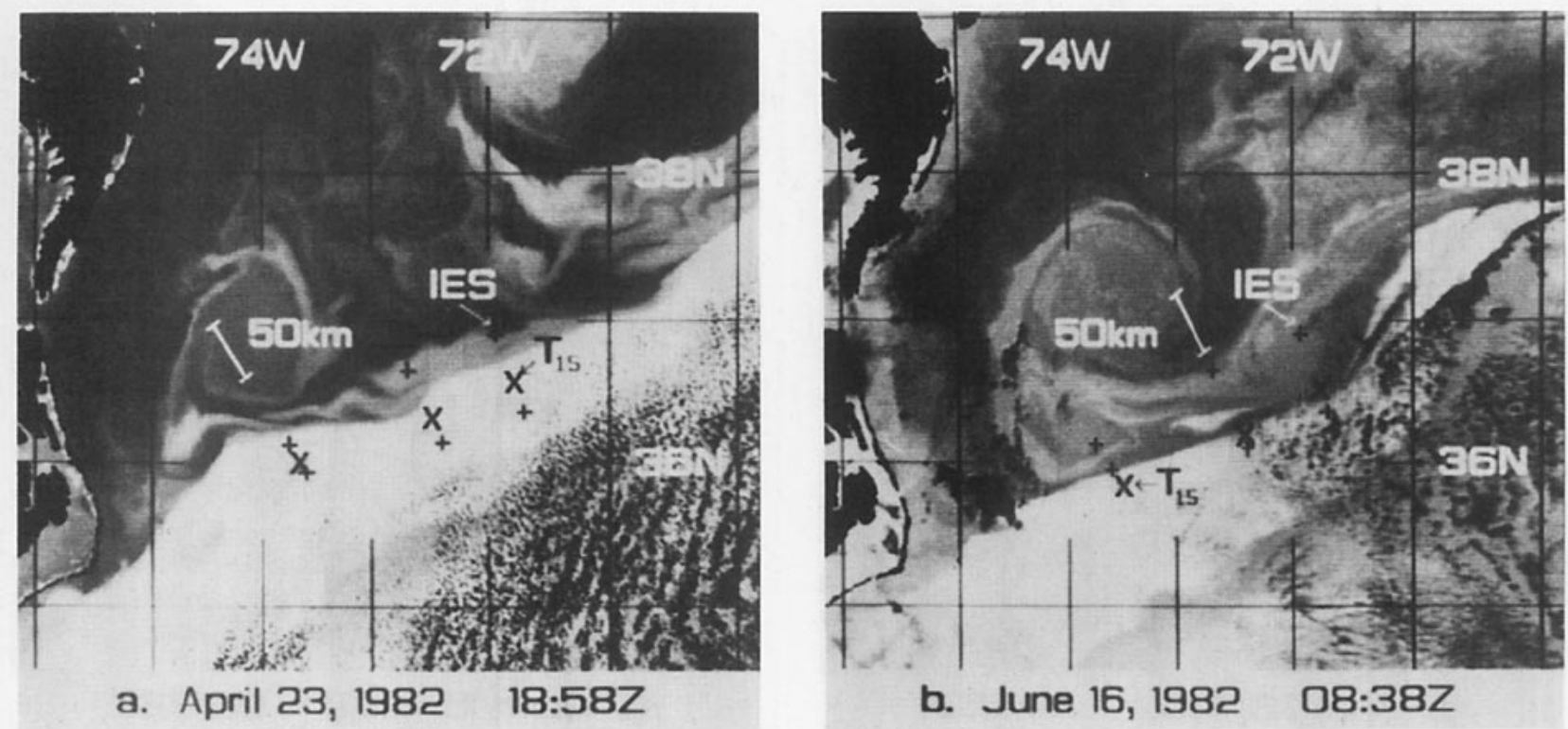

FIG. 2. Satellite images of AVHRR passes over IES deployment region. IES location of $T_{15}$ indicated by X. IES instruments indicated by +. Warm water white. Cool water dark. Grey shades monotonic in temperature. Clouds (in the lower right of each image) are black. (a) 23 April 1982. (b) 16 June 1982.

spikes or noise in the data. A $3 \times 3$ Sobel gradient operator (Duda and Hart, 1973) was then passed over the output of the median operator. The output of the Sobel gradient operation is the magnitude of the gradient at each pixel. The resulting image was then displayed on a color monitor along with the three IES lines along which IES data was collected simultaneously. An analyst defined the limits on each IES line beyond which the computer should disallow large gradients which were obviously not associated with the Gulf Stream, such as the shelf-slope front or warmcore rings; within these limits the computer determined the position of the maximum SST gradient. (These limits were defined subjectively only for convenience. It is quite straightforward to have the algorithm select these limits using historical data.) The analyst also assigned to each of the images a quality ranging from 0 , no useful data, to 3 , very clear. These quality ratings were used in the comparisons of the various methods. Figure 3 shows the magnitude of the gradient of each of the images in Fig. 2 along with the location of the maximum gradient $(\mathrm{X})$ for each IES line.

\section{2) MAXIMUM SST (TEMP)}

The maximum SST was picked in a fashion similar to that for the maximum SST gradient. Two extremes were subjectively selected along each IES line and the maximum SST (for NOAA-7 images) or maximum channel 4 radiance (for TIROS-N and NOAA- 6 images) was determined by the computer between the extremes. Each IES line was also assigned a quality.
Note that the quality associated with a given IES line may be different between the maximum SST and the maximum SST gradient because in general the two locations occur in different parts of the image. Often the Gulf Stream itself is covered with scattered clouds while the sharp gradient along its northern edge is clear. Figure 4 shows the location of the maximum temperature along each of the three IES lines as an X.

\section{3) CHANGE IN SIGN OF SKEW (SKEW)}

Using GOES satellite thermal IR data, Gerson et al. (1979) compared over twenty different methods of locating the Gulf Stream northern edge (based on pattern recognition techniques) with its location determined subjectively from the same data by a trained analyst. The location determined from a change in sign of the skew of the 25 SST values in a moving $5 \times 5$ pixel box led to the best results. The same statistic has been used in the present study. The line defined by the pixels along which the skew changes sign is taken as the edge of the Gulf Stream. The advantage of this statistic is that it highlights a local asymmetry in the SST field while averaging over a small region. The actual location was determined in much the same way as in the two previous cases. The image was displayed, an acceptable range was defined subjectively, the change in sign of the skew along this line was determined, and, finally, a subjective quality was assigned to the image. Figure 5 shows the location of the change in sign of the skew as $\mathrm{X}$. 


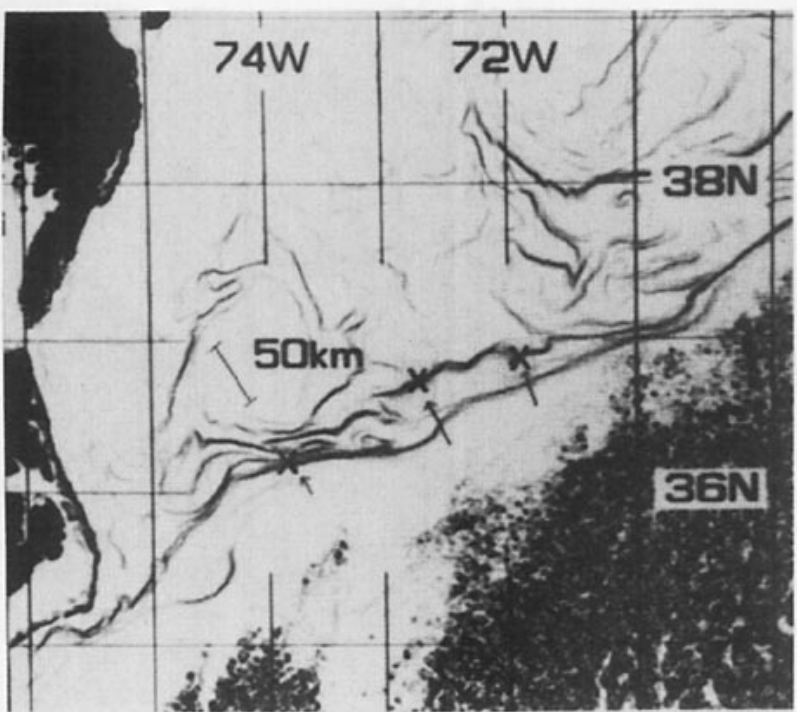

a. April 23, 1982

18:58Z

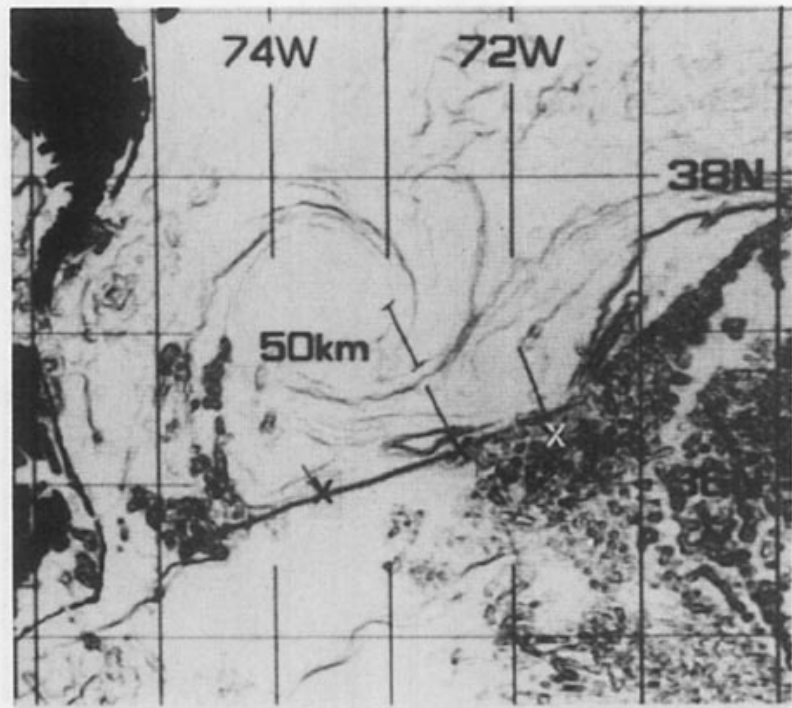

b. June $16,1982 \quad 08: 38 Z$

FIG. 3. Satellite images as in Fig. 2 but with the Sobel gradient operator passed over the image. The maximum gradient (GRAD) along the IES line is indicated by $X$. The arrow pointing to each $X$ originates at the southernmost IES in frame a and the northernmost IES in frame $b$ and is included to aid in locating the $X$.

\section{4) Maximum Variance (VAR)}

In an attempt to combine the high gradient feature of the northern edge of the Gulf Stream with an operator that uses a moderately large number of pixels and is hence statistically stable, the variance was also investigated. Each pixel in the image was replaced by the variance in a $7 \times 7$ pixel box centered on that pixel. The Gulf Stream edge was then defined as the point

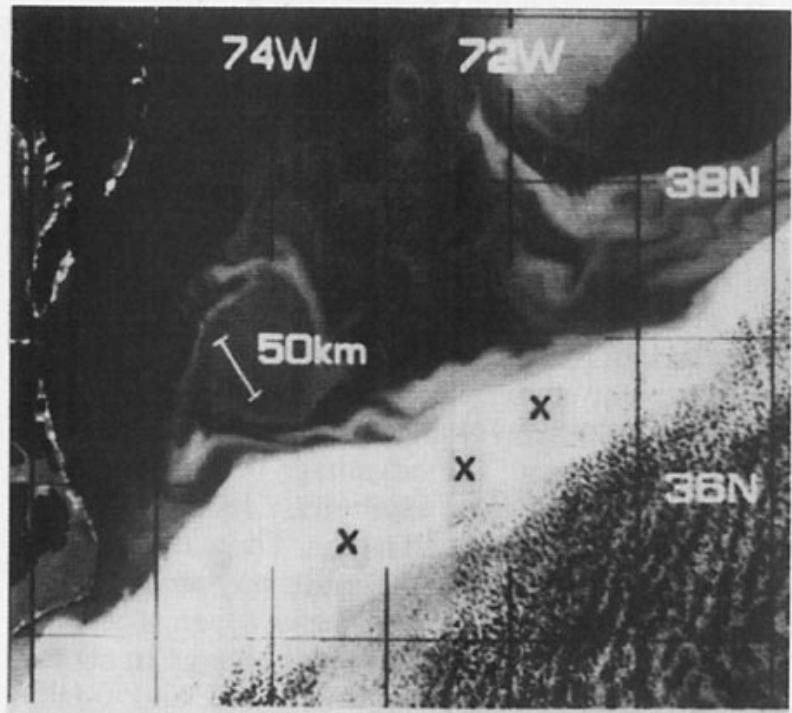

a. April 23, 1982 18:58Z of maximum variance lying between two extremes selected subjectively. Each IES line was also assigned a quality. In Fig. 6 the maximum variance along each line is indicated by $\mathrm{X}$.

\section{5) SUbJECTIVE LOCATION OF EDGE (EYE)}

Finally, in order to investigate the possibility that a better statistic exists than those outlined above, the Gulf

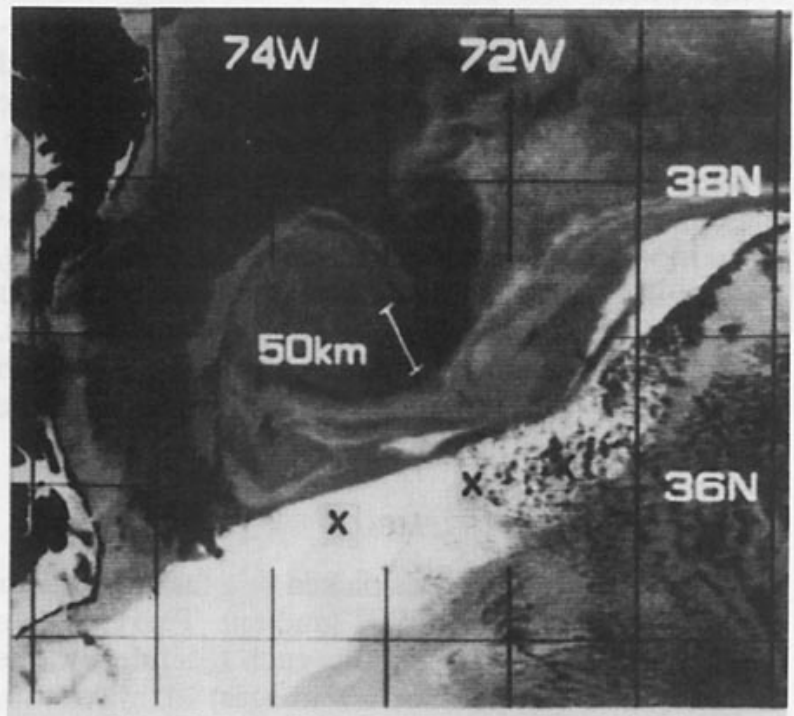

b. June 16, $1982 \quad 08: 38 Z$

FIG. 4. Same satellite images as in Fig. 2 with the location of the maximum temperature (TEMP) along each IES line indicated by X. 


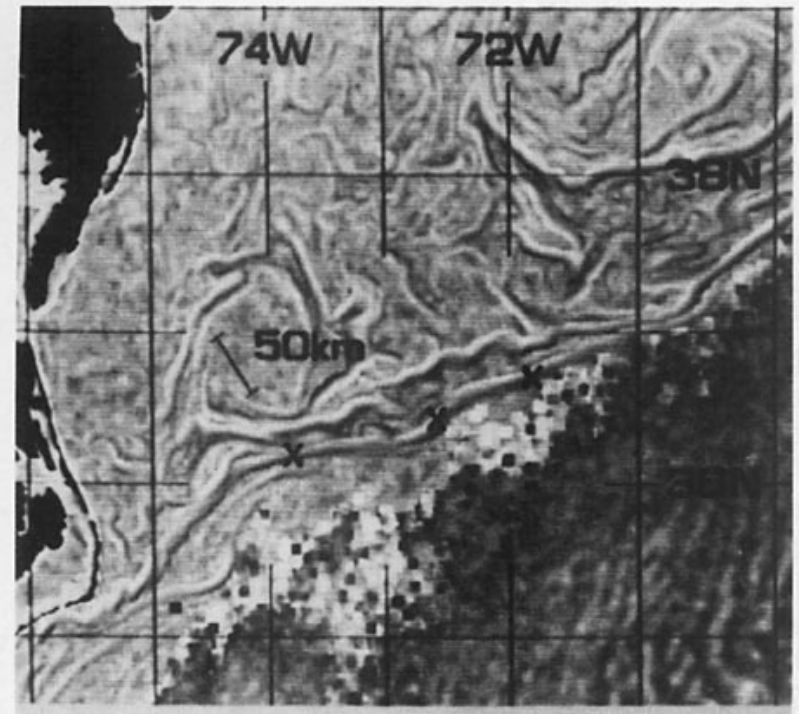

a. April 23,1982 18:58Z

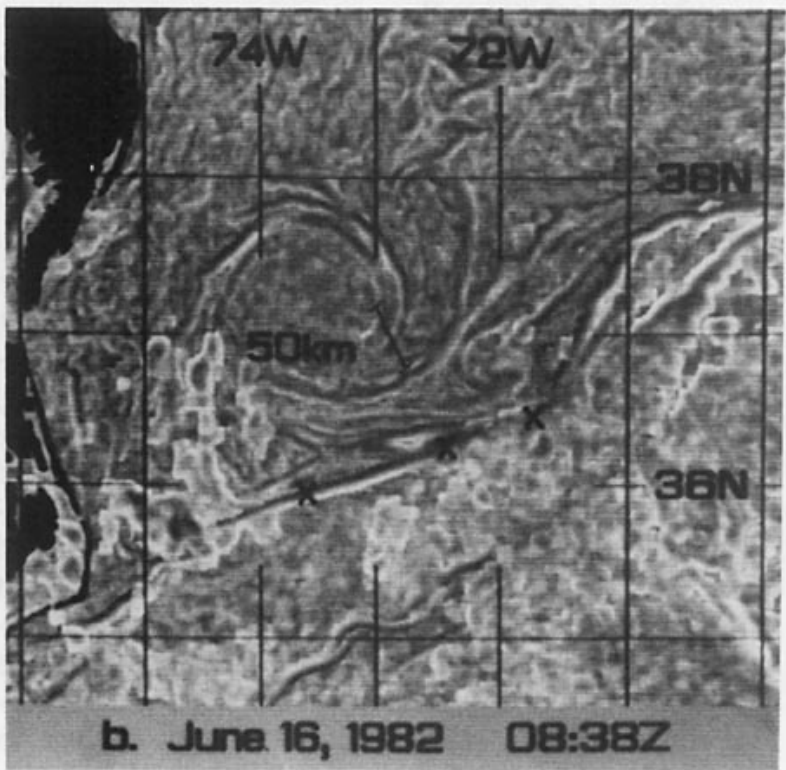

FlG. 5. Skew of the $5 \times 5$ pixel squares for the images of Fig. 2. Change in sign of skew (SKEW) along each IES line indicated by $X$.

Stream northern edge was subjectively located on the original image by one of the authors. Again, a quality was associated with each line. An analysis of the algorithm used by the analyst showed that it consisted of two steps. The contour selected 1) had to be "smooth" over a moderately long range $(30-50 \mathrm{~km}$ ), and 2) had to have a discernable gradient (i.e., it was not interpolated to lie in a low or zero gradient region). Step 1 assumed that a current such as the Gulf Stream cannot change its direction by a large amount (such as $40^{\circ}$ or $50^{\circ}$ ) in a distance of a few kilometers, hence the "smoothness" criterion. Once the smoothest con-

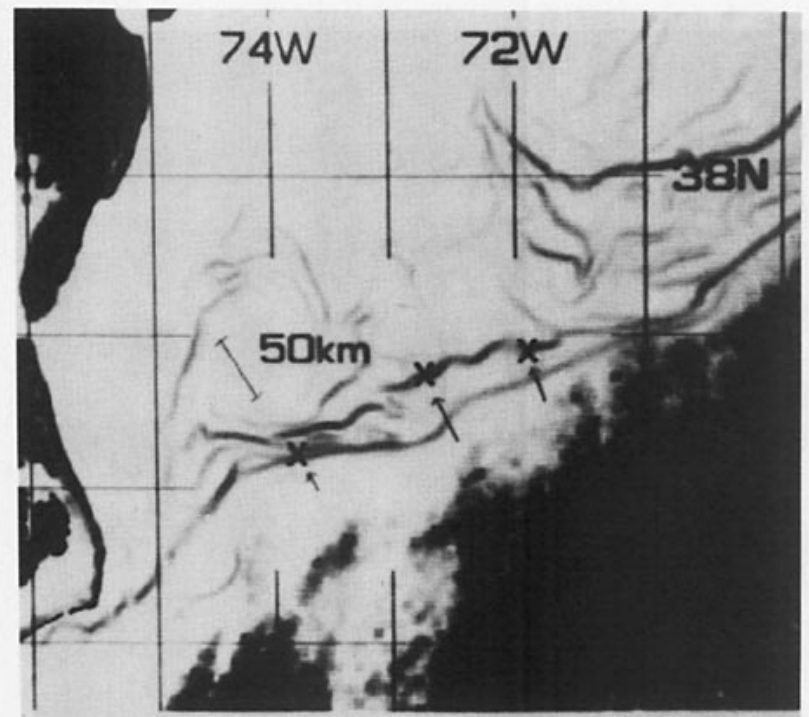

a. April 23, $1982 \quad 18: 58 Z$

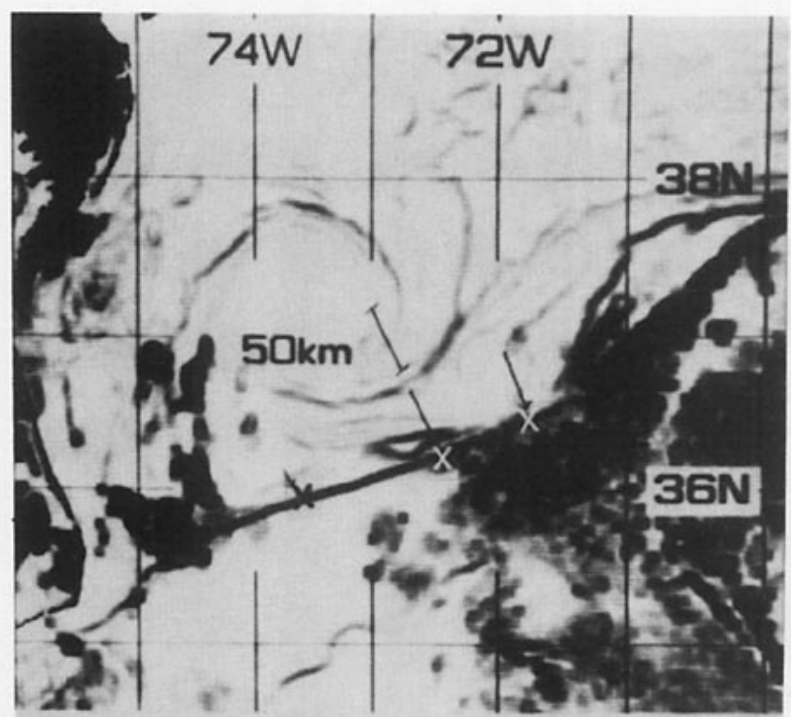

b. June $16,1982 \quad 08: 382$

FIG. 6. Variance of $7 \times 7$ pixel squares for the images of Fig. 2. The maximum variance (VAR) along each IES line is indicated by X. The arrow pointing to each $X$ originates at the southernmost IES along the line in frame a and the northernmost IES along the line in frame b. 
tour was located, a smaller region was used to pick the actual location of the northern edge. Thus the algorithm was anisotropic in nature, integrating the continuity in the along-stream direction (the first step) with the sharp change in the across-stream direction (the second step).

The "smoothness" of the contour defined in the first step in general leads to the southernmost gradient on the shoreward side of the stream being chosen. Horton (1984) also consistently selected the southernmost gradient (which he referred to as the warmest gradient) when more than one was apparent. The disadvantage with this technique is that the actual gradient selected depends on the visibility of gradients in the image. Under poor visibility due to high humidity, scattered clouds or low thermal contrast, the maximum gradient is selected. As the visibility improves, the gradient selected could change. This could result in inconsistencies from one day to the next as surface mixing affects thermal contrast or as atmospheric conditions change. In Fig. 7, the subjective locations of the northern edge from three separate analyses of the data for each IES line are shown by Xs. Note that one of the locations on the upstream line in Fig. $7 \mathrm{~b}$ is about $10 \mathrm{~km}$ seaward (on a very faint edge) of the outer two. On all other lines all three Xs are essentially superimposed.

\section{Discussion}

\section{a. Image quality estimation}

Several points should be noted about the subjectively determined "quality" before comparing the methods.

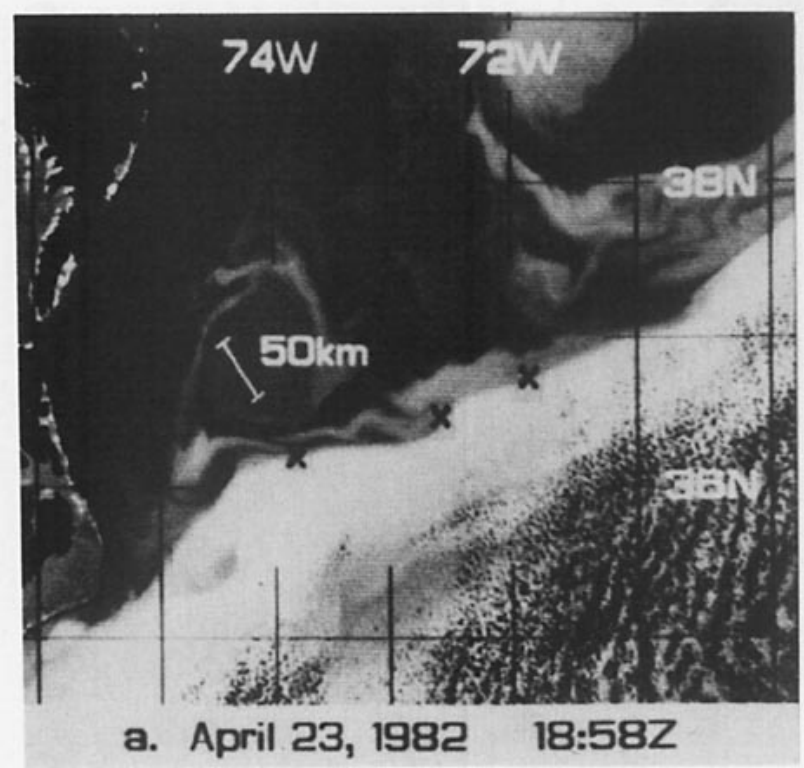

To begin with, the determination is very subjective. The overall analysis was repeated three times by the same observer on a subset of the images and the correlation coefficients between the "qualities" in the three sets taken pairwise were $0.53,0.56$ and 0.70 . The pair of analyses with the highest correlation coefficient were performed within a few weeks of one another while the third analysis was performed several months earlier. Second, all of the objectively determined northern edge positions, (GRAD, TEMP, SKEW and VAR) were rated by one analyst and the subjective northern edge determination (EYE) by another analyst. Third, the "quality" of the image will clearly vary from method to method since the various methods address different parts of the image and the processing of the image varies (see Figs. 3-6). Despite these differences, the following general remarks are true. A quality of less than 1.0 indicates no useful estimate. A quality between 1.0 and 2.0 indicates that an estimate was obtained but with difficulty due to clouds in the area, low thermal contrast or multiple fronts. Finally, a quality between 2.0 and 3.0 indicates a good estimate, with those above 2.5 indicating very clear imagery.

\section{b. Quality $\geqslant 2.5$}

Because of the subjectivity of the quality, we begin by comparing only the clearest satellite observations with the IES data. In Table 2, SAT distances (distances from the northernmost IES instrument on the IES line to the satellite-derived Gulf Stream northern edge) from each method where image quality $\geqslant 2.5$ are compared with IES distances (distances from the northernmost

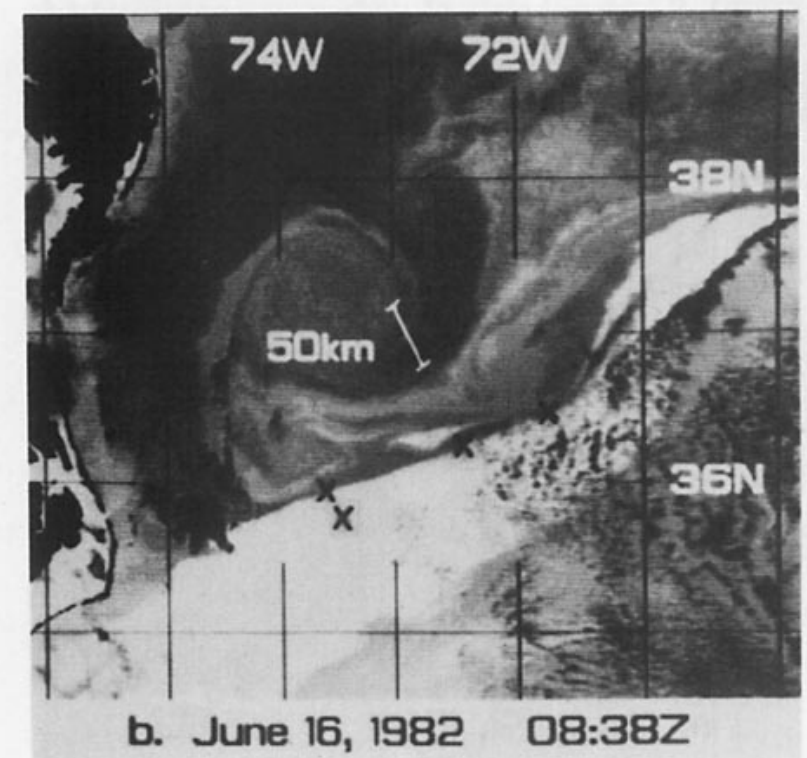

FIG. 7. Same satellite image as in Fig. 2 with the subjective location (EYE) of the Gulf Stream edge made on three separate occasions for each IES line and indicated by $\mathrm{X}$. 
TABLE 2. Statistical comparison of the five satellite methods of locating the Gulf Stream northern edge with the IES-derived $T_{15}$ for image quality $\geqslant 2.5$.

\begin{tabular}{|c|c|c|c|c|c|c|c|c|c|c|c|}
\hline \multirow[b]{2}{*}{$\begin{array}{l}\text { Satellite } \\
\text { method }^{\mathrm{a}}\end{array}$} & \multirow[b]{2}{*}{$\begin{array}{c}\text { Number } \\
\text { of } \\
\text { observations }\end{array}$} & \multirow[b]{2}{*}{$\begin{array}{l}\sigma_{\mathrm{SAT}}{ }^{\mathrm{b}} \\
(\mathrm{km})\end{array}$} & \multirow[b]{2}{*}{$\begin{array}{l}\sigma_{\mathrm{IES}}^{\mathrm{c}} \\
(\mathrm{km})\end{array}$} & \multirow[b]{2}{*}{$A^{\mathrm{d}}$} & \multirow[b]{2}{*}{$\begin{array}{c}B^{\mathbf{d}} \\
(\mathbf{k m})\end{array}$} & \multirow{2}{*}{$\boldsymbol{R}^{\mathbf{e}}$} & \multirow[b]{2}{*}{$A / R^{\mathrm{f}}$} & \multirow[b]{2}{*}{$\begin{array}{l}\text { SAT-IES }^{\mathbb{8}} \\
(\mathrm{km})\end{array}$} & \multirow[b]{2}{*}{$\begin{array}{c}\sigma_{\text {SAT-IES }}{ }^{h} \\
(\mathrm{~km})\end{array}$} & \multicolumn{2}{|c|}{$\begin{array}{c}\text { Corrected for crossing } \\
\text { angle }\end{array}$} \\
\hline & & & & & & & & & & $\begin{array}{l}\text { SAT-IES }_{\perp}{ }^{i} \\
(\mathrm{~km})\end{array}$ & $\underset{(\mathrm{km})}{\sigma_{\mathrm{SAT-IES}_{\perp}{ }^{j}}}$ \\
\hline EYE & 145 & 36.7 & 30.0 & 0.75 & 13.0 & 0.92 & 0.82 & -8.2 & 15.2 & -7.5 & 14.0 \\
\hline SKEW & 84 & 36.7 & 31.1 & 0.70 & 18.7 & 0.82 & 0.85 & -15.1 & 20.8 & -14.0 & 19.6 \\
\hline GRAD & 98 & 39.6 & 33.4 & 0.73 & 19.2 & 0.86 & 0.85 & -16.6 & 20.0 & -15.8 & 19.2 \\
\hline VAR & 89 & 41.8 & 33.9 & 0.70 & 25.5 & 0.86 & 0.81 & -23.2 & 21.5 & -21.9 & 20.7 \\
\hline TEMP & 108 & 34.4 & 29.8 & 0.70 & -9.4 & 0.81 & 0.86 & 26.5 & 20.3 & 25.1 & 19.4 \\
\hline
\end{tabular}

aethod codes defined in text.

b Standard deviation of the satellite distances, SAT (the distance from the northernmost IES instrument to the satellite-derived location of the Gulf Stream northern edge along an IES line).

c Standard deviation of the IES distances, IES (the distance from the northernmost IES instrument to the IES-derived location of $T_{15}$ along an IES line).

${ }^{d}$ Regression coefficients of the IES distances on the SAT distances: IES $=A * \mathrm{SAT}+B$.

- Correlation coefficient between the SAT and IES distances.

'Unbiased regression coefficient for $A$.

B SAT distance minus IES distance.

${ }^{\mathrm{h}}$ Standard deviation of $\mathrm{g}$, above.

i Difference between SAT distance and IES distance along a line normal to the northern edge defined by the IES-derived $T_{15}$. The crossing angle between the Gulf Stream and the IES line was derived from data from pairs of IES lines.

${ }^{\mathrm{j}}$ Standard deviation of $i$.

IES to the IES-derived $T_{15}$ ). The most obvious conclusion from Table 2 is that EYE (the subjective method) is a significantly better predictor of the IES-derived $T_{15}$ than any of the objective measures. This can be seen in the correlation coefficient $(R)$ or the standard deviations of the satellite data about the IES data $\left(\sigma_{\text {SAT-IES }}\right.$ or $\left.\sigma_{\text {SAT-IES }}\right)$. The difference between the corrected standard deviation $\left(\sigma_{\mathrm{SAT}-\mathrm{IES} \mathrm{S}_{\perp}}\right)$ resulting from EYE and those from any of the objective measures is statistically significant at the $99 \%$ confidence level using the standard $F$-test (Ostle and Mensing, 1957). The same test applied to corrected standard deviations within the group of objective measures does not show these as being statistically different at the $99 \%$ confidence level.

A second observation of interest about Table 2 is that regardless of the method used, subjective or objective, the unbiased regression coefficient $(A / R)$ of the IES data on the satellite data ranges from 0.81 to 0.86 , significantly less than 1.0. This means that the location of the northern edge determined from satellite data has relatively larger excursions than does the IES-derived $T_{15}$. The uncertainty (rms about the mean) associated with this coefficient is on the order of 0.02 ; hence, the values are quite significant.

The mean offset (SAT-IES ${ }_{\perp}$ ) of the satellite-derived front normal to the IES-derived $T_{15}$ is shoreward (i.e., negative) in all cases except for TEMP, which makes use of the maximum temperature and will, therefore, in general be seaward of $T_{15}$. The other measures identify in one fashion or another an SST gradient. Second, excluding TEMP, the shoreward offset is smallest for the subjective method (EYE) because it makes use of the warmest gradient.

A final point to consider about Table 2 is the difference between the number of observations for the subjective method and those for the objective methods. Given that the pool of images used is the same in all cases, there are two possible explanations for the significantly higher number of images used (quality $\geqslant 2.5$ ) for EYE (145) than for SKEW, GRAD, VAR and TEMP (ranging from 84 to 108). Either the analyst was more generous in rating the images for EYE or the additional processing required for SKEW, GRAD and VAR tended to decrease the quality of the image. Both TEMP and EYE used the same images but were on the average dealing with regions separated by $35 \mathrm{~km}$. Whatever the cause for these differences, the fact that there are more subjective observations tends to strengthen the general conclusion that the subjective method used is the best predictor of the IES-derived $T_{15}$ because the more images included, the poorer the average quality.

\section{c. Quality $\geqslant 1.0$}

Table 3 is identical to Table 2 except that the statistics presented are for images with quality $\geqslant 1.0$; i.e., all images for which an estimate was considered to be possible were used. The number of data points is approximately tripled in all cases. Here also, the subjective technique is better than the objective ones. In fact, most of the characteristics for both EYE and SKEW remain virtually unchanged. This is not true of the other ob- 
TABLE 3. Statistical comparison of the five satellite methods of locating the Gulf Stream northern edge with the IES-derived $T_{15}$ for image quality $\geqslant 1.0 .^{*}$

\begin{tabular}{|c|c|c|c|c|c|c|c|c|c|c|c|}
\hline \multirow[b]{2}{*}{$\begin{array}{l}\text { Satellite } \\
\text { method }\end{array}$} & \multirow[b]{2}{*}{$\begin{array}{c}\text { Number } \\
\text { of } \\
\text { observations }\end{array}$} & \multirow[b]{2}{*}{$\begin{array}{r}\sigma_{\mathrm{SAT}} \\
(\mathrm{km})\end{array}$} & \multirow[b]{2}{*}{$\begin{array}{c}\sigma_{\text {IES }} \\
(\mathrm{km})\end{array}$} & & \multirow[b]{2}{*}{$\begin{array}{c}B \\
(\mathrm{~km})\end{array}$} & \multirow[b]{2}{*}{$R$} & \multirow[b]{2}{*}{$A / R$} & \multirow[b]{2}{*}{$\begin{array}{l}\text { SAT-IES } \\
(\mathrm{km})\end{array}$} & \multirow[b]{2}{*}{$\begin{array}{c}\sigma_{\text {SAT-IES }} \\
(\mathrm{km})\end{array}$} & \multicolumn{2}{|c|}{$\begin{array}{c}\text { Corrected for crossing } \\
\text { angle }\end{array}$} \\
\hline & & & & & & & & & & $\begin{array}{l}\text { SAT-IES }_{\perp} \\
(\mathrm{km})\end{array}$ & $\begin{array}{c}\sigma_{\mathrm{SAT}-\mathrm{IES}_{\perp}} \\
(\mathrm{km})\end{array}$ \\
\hline EYE & 358 & 36.8 & 30.8 & 0.76 & 14.0 & 0.91 & 0.84 & -9.8 & 15.6 & -9.0 & 14.3 \\
\hline SKEW & 312 & 38.2 & 30.4 & 0.68 & 19.6 & 0.86 & 0.79 & -15.1 & 19.5 & -14.0 & 18.2 \\
\hline GRAD & 288 & 42.4 & 31.4 & 0.61 & 24.1 & 0.82 & 0.74 & -22.1 & 24.4 & -20.6 & 22.9 \\
\hline VAR & 295 & 39.8 & 29.9 & 0.59 & 25.1 & 0.78 & 0.76 & -22.0 & 24.7 & -20.7 & 23.5 \\
\hline TEMP & 370 & 40.3 & 30.2 & 0.46 & 0.6 & 0.61 & 0.75 & 31.6 & 32.3 & 29.7 & 30.6 \\
\hline
\end{tabular}

* Column headings as in Table 2.

jective measures, which appear to suffer from degradation in image quality. The correlation coefficient between TEMP (maximum temperature) determinations of the northern edge and the IES-derived $T_{15}$ decreases from 0.81 for a quality $\geqslant 2.5$ to 0.61 for quality $\geqslant 1.0$. There is, of course, a concomitant increase in the standard deviation of the corrected differences $\left(\sigma_{\text {SAT-IES }}\right)$.

The standard deviation ( $\left.\sigma_{\text {SAT-IES }}\right)$ of the subjective method, EYE, is statistically different from that obtained by the SKEW method at the $99 \%$ confidence level. Similarly the standard deviation obtained using the SKEW method is statistically different from that obtained using the GRAD method.

A significant difference between the various methods is the number of SST elements used in the determination of the Gulf Stream's northern edge; the more elements used, the better the estimate and the less sensitive it is to the quality of the image (except in the case of the variance, VAR). Although difficult to quantify, the subjective method makes use of the most spatial information, beginning with a region of at least 30 by $100 \mathrm{~km}$. The variance operator used a $7 \times 7 \mathrm{~km}$ square but is very susceptible to clouds. The skew operator makes use of $5 \times 5 \mathrm{~km}$ squares. The gradient uses $3 \times 3 \mathrm{~km}$ squares, and the maximum temperature uses on pixel, or $1 \times 1 \mathrm{~km}$. There is clearly a limit to how large the area used can be and still provide good results. As the area becomes larger, more data are averaged together, hence the increased stability with regard to image quality. At the same time, as the area increases, the spatial resolution for locating the edge decreases. The anisotropic nature of the subjective algorithm using two separate scales circumvents this problem. Future objective algorithms must achieve the appropriate balance between the use of large spatial regions focussing on the continuity of the along-stream edge and the use of smaller spatial regions focussing on the sharpness of the across-stream step.

Figure 8 shows the IES distances plotted against the SAT distances for all subjective determinations of quality $\geqslant 1.0$. The best fit straight line and the $95 \%$ confidence lines are also included. The large range in data, -60 to $+80 \mathrm{~km}$, is clear from this figure as is the small number of very large deviations from the best fit regression line. Of the 358 deviations, three are between 40 and $50 \mathrm{~km}$ (circles) and two are between 30 and 40 km (triangles).

The configurations of the Gulf Stream for four of the five largest deviations are shown in Fig. 9, along with the IES line. These four cases arise from two separate events, both with abnormally large meanders (large wavenumber and large amplitude) for the Cape Hatteras region with significant shingling at the IES line. The September 1981 event propagated through all three IES lines with a large deviation first on line B (12 September 1981; Fig. 9a), then on line D (13 September 1981; Fig. 9b), and finally on E (15 September 1981; Fig. 9c). The observations on lines B and D, in the trough of the meander, show that the satellite derived surface front (circles) is seaward of the IESderived $T_{15}$ locations (squares). The observation on line $\mathrm{E}$ at the following crest downstream (Fig. 9c) shows a large shoreward deviation of the surface front. The other two deviations which exceeded $30 \mathrm{~km}$ occurred in May 1982. Only that at 0652 UTC 5 May 1982 is shown in Fig. 9; the other occurred approximately 90 minutes later (at 0834 UTC) and is similar.

\section{d. Offsets and error analysis for all usable images}

In the preceding we have established a linear relationship between the satellite-derived surface front and the IES-derived $T_{15}$ : IES $=A * \mathrm{SAT}+B$, where IES and SAT are the distances along the IES line from the northernmost IES instrument to $T_{15}$ and to the satellitederived surface front, respectively. The satellite-derived surface front may therefore be used to estimate $T_{15}$ : the distance of the surface front from the northernmost IES (along an IES line) is scaled by $A=0.76$ and offset to the southeast by $B=14.0 \mathrm{~km}$ (for method EYE in Table 3). The scatter of this estimate about the IESderived $T_{15}$ is found to be $12.9 \mathrm{~km}$. Ultimately, how- 


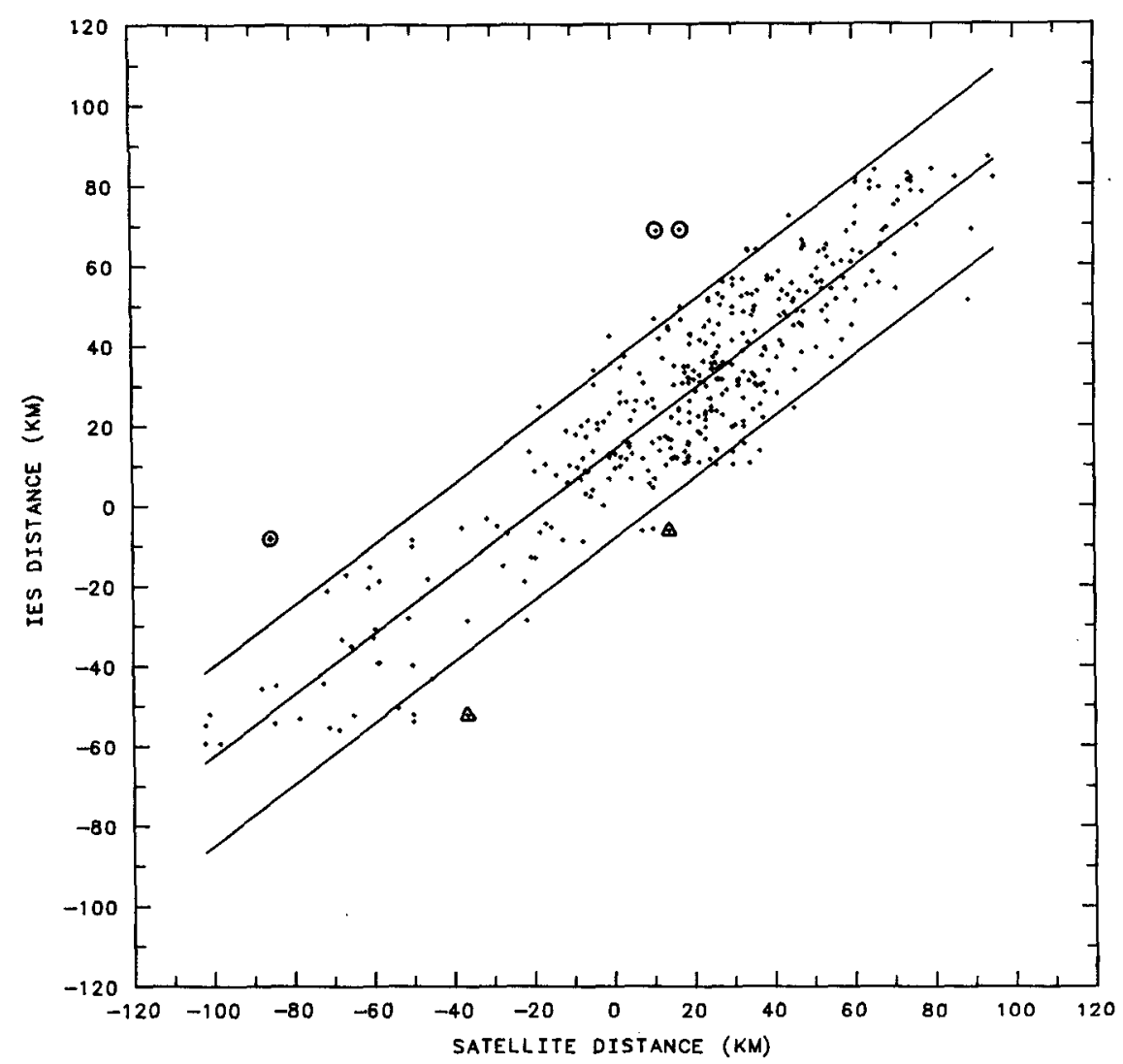

FIG. 8. IES distance (distance from the northernmost IES to the IES-derived $T_{15}$ on an IES line) versus SAT distance (distance from the same IES to the satellite-derived northern edge on the same line) for all observations with a quality $\geqslant 1.0$.

ever, one would like to know how accurately $T_{15}$ derived from the satellite data compares to the true value of $T_{15}$ and not to the IES- or XBT-derived $T_{15}$. In order to estimate this, we assume that $T_{15}$ obtained from the satellite-derived surface front, from the IES data, from the XBT data, and from the XBT-derived surface front are independent measures of the true $T_{15}$.

Given this assumption, we obtain the following relations:

$$
\begin{array}{ll}
\sigma_{\mathrm{SAT}}^{2}+\sigma_{\mathrm{IES}}^{2}=12.9^{2} & \text { (1) This study } \\
\sigma_{\mathrm{ZBT}}^{2}+\sigma_{\text {IES }}^{2}=8.0^{2} & \text { (2) Watts and Johns (1982) } \\
\sigma_{\mathrm{SHIP}}^{2}+\sigma_{\mathrm{XBT}}^{2}=11.8^{2} & \text { (3) Hansen and Maul (1970) }
\end{array}
$$

where

$\sigma_{\mathrm{SAT}} \quad$ the scatter of the satellite-derived $T_{15}$ about the true $T_{15}$,

$\sigma_{\text {IES }}$ the scatter of the IES-derived $T_{15}$ about the true $T_{15}$,

$\sigma_{\text {XBT }}$ the scatter of the XBT-derived $T_{15}$ about the true $T_{15}$, and $\sigma_{\text {SHIP }}$ the scatter of $T_{15}$ about the ship-derived surface front.

We note that Hansen and Maul (1970) make no mention of the regression coefficient of $T_{15}$ on the surface front; i.e., in calculating the scatter of the surface front about $T_{15}$, a regression coefficient of 1.0 is assumed. In our study the regression coefficient was determined to be 0.76 but it appears to increase toward 1.0 downstream from Cape Hatteras (not shown). If this trend continues, the difference of the slope from 1.0 in Hansen and Maul's (1970) work would be small since their observations extend from Cape Hatteras to $58^{\circ} \mathrm{W}$. We have therefore assumed a regression coefficient of 1.0 for Hansen and Maul's work.

Watts and Johns (1982) estimated $\sigma_{\text {IES }}$ to be $5 \mathrm{~km}$ from the coherence between successive downstream IES sites. From Eq. 1 we then have an estimate of $\sigma_{\mathrm{SAT}}$ $\approx 11.9 \mathrm{~km}$; from equation $2, \sigma_{\mathrm{XBT}} \approx 6.2 \mathrm{~km}$; and from equation $3, \sigma_{\mathrm{SHIP}} \approx 10.0 \mathrm{~km}$. If, on the other hand, $\sigma_{\mathrm{IES}}$ is $8 \mathrm{~km}$, then $\sigma_{\mathrm{SAT}}=10.1 \mathrm{~km}, \sigma_{\mathrm{XBT}}=0 \mathrm{~km}$, and $\sigma_{\text {SHIP }}=11.8 \mathrm{~km}$. Thus, at best the scatter of the satellite-derived $T_{15}$ about the true $T_{15}$ is $10.1 \mathrm{~km}$ and 

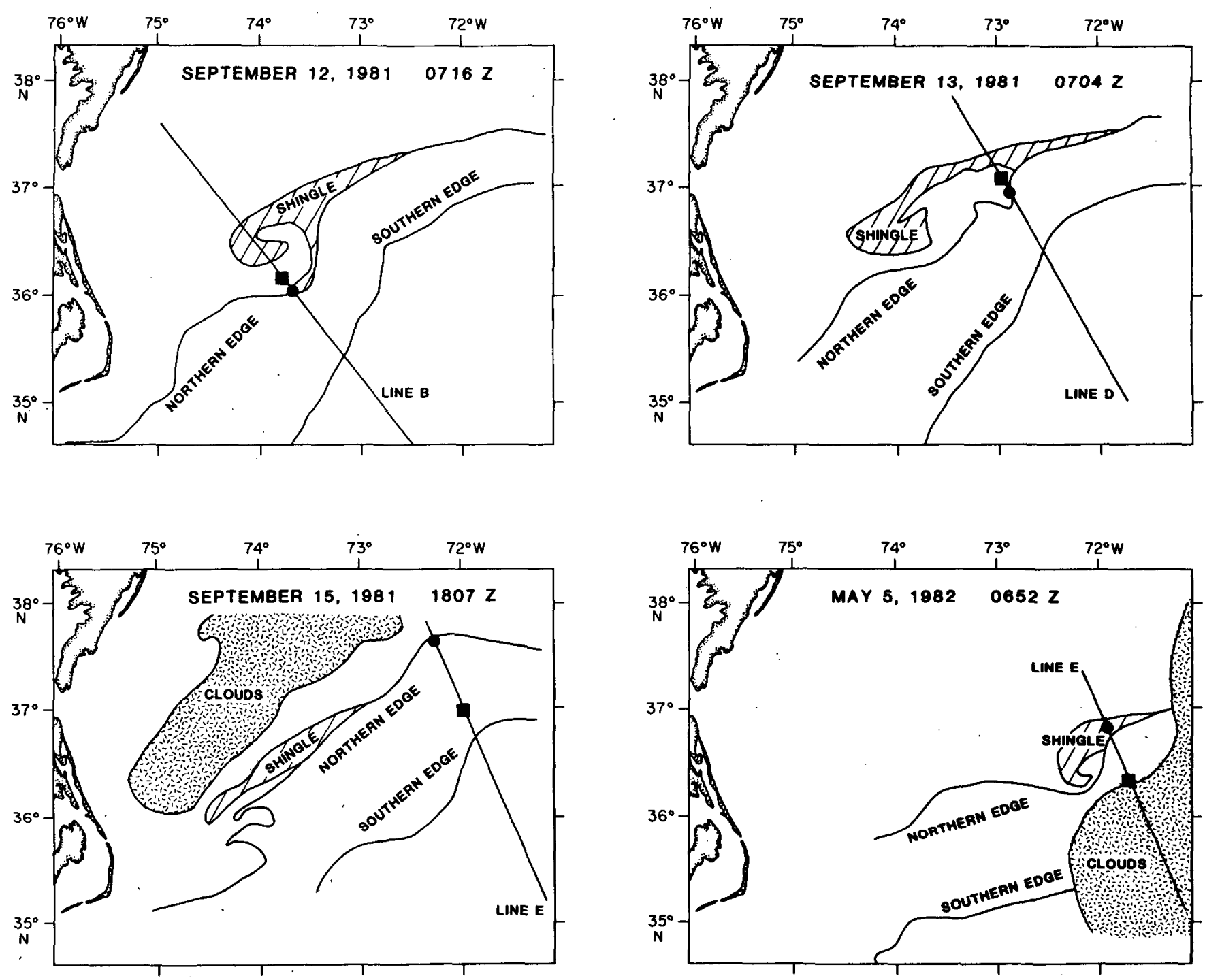

FIG. 9. The Gulf Stream surface fronts and the IES-derived location of $T_{15}$ for observations having large deviations in Fig. 8 between the predicted location of $T_{15}$ using satellite data and the IES location of $T_{15}$. A circle marks the satellite-derived front on the IES line. A square locates the IESderived $T_{15}$. Hachured regions designate shingling. Stippled areas are clouds. (a, b, c) September 1981. (d) May 1982.

at worst $11.9 \mathrm{~km}$, quite consistent with the range of Hansen and Maul's (1970) ship-derived $T_{15}$ using surface XBT data.

Because the atmospherically corrected NOAA-7 data appears to show the Gulf Stream structure more clearly than the uncorrected data from TIROS-N and NOAA6, a comparison was performed on all NOAA-7 passes used between the Gulf Stream edges located subjectively in the uncorrected channel 4 and channel $5 \mathrm{im}$ ages and those in the corrected images. The resulting three datasets were statistically indistinguishable for quality 1.0 and better images. In other words, atmospheric correction using channels 4 and 5 does not appear to aid significantly in the subjective location of the front.

\section{Summary}

In this work, the northern edge of the Gulf Stream off Cape Hatteras, North Carolina was located in 155 AVHRR-derived maps of sea surface temperature (SST) using five different methods. These observations were then compared with the location of $T_{15}$ determined from inverted echo sounders (IESs) sitting on the sea floor. Of the methods used, one consisted of subjective location of the edge by an analyst and the others consisted of objective location of the edge by computer using various statistics of the SST field. The method giving the best fit, defined as having the smallest rms difference between the IES-derived $T_{15}$ and the satellite surface front, is the subjective one. On the av- 
erage, the analyst located the surface front $9.0 \mathrm{~km}$ shoreward of $T_{15}$ with a rms difference of $14.3 \mathrm{~km}$ (Table 3). The rms difference about the best-fit regression line of $T_{15}$ on the satellite-derived surface front is $12.9 \mathrm{~km}$.

The best of the objective methods makes use of the skew in the SST field. The skewness of $5 \times 5$ pixel squares changes sign as the edge of the Gulf Stream is crossed. The surface front as determined using skewness was $14.0 \mathrm{~km}$ shoreward of $T_{15}$ and the rms deviation was $18.2 \mathrm{~km}$ (Table 3 ). This rms deviation was significantly less than the $22.9 \mathrm{~km}$ determined using the maximum gradient, the generally accepted measure of the edge. Of more significance is the finding that as the quality of the image decreases, the objective measures using either the maximum gradient, the maximum temperature or the maximum variance as an indication of the edge perform more and more poorly. This is not true of the subjective measure or the use of skewness. For these methods the accuracy of the location of the edge was only marginally affected by the quality of the data as long as an estimate was possible.

The best algorithm, the subjective one, is anisotropic in nature, requiring along-stream continuity of the surface gradient over a distance of about $100 \mathrm{~km}$ and a sharp across-stream step over a distance of order 10 $\mathrm{km}$. It is also apparent that to a limit the more elements used in an algorithm, the more stable the algorithm is with regard to image quality.

It has been demonstrated that satellite data can be used to locate the surface front relative to $T_{15}$ with as much accuracy as has been done with surface readings from XBT data (Hansen and Maul, 1970).

Acknowledgments. This research has been supported by the National Science Foundation through grants OCE 82-14958 and OCE 82-01222. We thank G. Epstein and $\mathrm{K}$. Tracey for help with the data processing and J. Rahn for editing the manuscript. The image processing software was developed by R. Evans, $O$. Brown, J. Brown, and A. Li at the University of Miami under Office of Naval Research funding. The continuing support of the Miami group is gratefully acknowledged.

\section{REFERENCES}

Chaplin, G., and D. R. Watts, 1984: Inverted echo sounder development, Oceans '84 Conference Record. 1, 249-253.

Duda, R., and P. Hart, 1973: Pattern Classification and Scene Analysis, Wiley and Sons, New York.

Fuglister, F. C., and L. V. Worthington, 1951: Some results of a multiple ship survey of the Gulf Stream. Tellus, 3, 1-14.

Gerson, D. J., and P. Gaborski, 1977: Pattern analysis for automatic location of oceanic fronts in digital satellite imagery. NAVOCEANO TN3700-65-77, U.S. Navy, Naval Oceanographic Office, Washington, DC, $67 \mathrm{pp}$.

Gerson, D., E. Khedouri and P. Gaborski, 1979: Detecting the Gulf Stream from digital infrared data using pattern recognition. Paper presented at the IGOSS Seminar, Moscow, April 2-11.

Hansen, D. V., and G. A. Maul, 1970: A note on the use of sea surface temperature for observing ocean currents. Remote Sens. Environ., 1, 161-164.

Horton, C. W., 1984: Surface front displacement in the Gulf Stream by hurricane/tropical storm Dennis. J. Geophys. Res., 89, 20052012.

Khedouri, E., 1972: Gulf Stream Monthly Summary, 7, No. 2.

McClain, E. P., W. G. Pichel, C. C. Walton, Z. Ahmad and J. Sutton, 1983: Multi-channel improvements to satellite-derived global sea surface temperatures. Adv. Space Res., 2(6), 43-47.

Ostle, B., and R. W. Mensing, 1957: Statistics in Research, Iowa State University Press.

Robinson, A. R., J. R. Luyten and F. C. Fuglister, 1974: Transient Gulf Stream meandering. Part I: An observational experiment. J. Phys. Oceanogr., 4, 237-255.

Schwalb, A., 1978: The TIROS-N/NOAA A-G satellite series, NOAA Tech. Memo. NESS 95, National Environmental Satellite Service, NOAA, U.S. Dept. of Commerce.

Stommel, H., W. S. Von Arx, D. Parson and W. S. Richardson, 1953: Rapid aerial survey of Gulf Stream with camera and radiation thermometer. Science, 117, 639-640.

Strack, S. L., 1953: Surface temperature gradients as indicators of the position of the Gulf Stream. WHOI Tech. Rep. 53-53, 24 pp.

Tracey, K. L., and D. R. Watts, 1986: On Gulf Stream meander characteristics near Cape Hatteras. J. Geophys. Res., 91, 75877602.

Watts, D. R., and W. E. Johns, 1982: Gulf Stream meanders: Observations on propagation and growth. J. Geophys. Res., 87, 9467-9476. 